\title{
Thunderstorm Cloud-Type Classification from Space-Based Lightning Imagers
}

\author{
Michael PETERSON \\ ISR-2, Los Alamos National Laboratory, Los Alamos, New Mexico \\ SCOTT RUDLOSKY \\ NOAA/NESDIS/STAR, SCSB, College Park, Maryland
}

DAILE ZHANG

Cooperative Institute for Satellite Earth System Studies, University of Maryland, College Park, College Park, Maryland

(Manuscript received 8 November 2019, in final form 3 March 2020)

\begin{abstract}
The organization and structure of thunderstorms determines the extent and severity of their hazards to the general public and their consequences for the Earth system. Distinguishing vigorous convective regions that produce heavy rain and hail from adjacent regions of stratiform clouds or overhanging anvil clouds that produce light to no rainfall is valuable in operations and physical research. Cloud-type algorithms that partition convection from stratiform regions have been developed for space-based radar, passive microwave, and now Geostationary Operational Environmental Satellites (GOES) Advanced Baseline Imager (ABI) multispectral products. However, there are limitations for each of these products including temporal availability, spatial coverage, and the degree to which they based on cloud microphysics. We have developed a cloud-type algorithm for GOES Geostationary Lightning Mapper (GLM) observations that identifies convective/nonconvective regions in thunderstorms based on signatures of interactions with nonconvective charge structures in the lightning flash data. The GLM sensor permits a rapid $(20 \mathrm{~s})$ update cycle over the combined GOES-16-GOES-17 domain across all hours of the day. Storm regions that do not produce lightning will not be classified by our algorithm, however. The GLM cloud-type product is intended to provide situational awareness of electrified nonconvective clouds and to complement other cloud-type retrievals by providing a contemporary assessment tied to lightning physics. We propose that a future combined ABI-GLM cloud-type algorithm would be a valuable product that could draw from the strengths of each instrument and approach.
\end{abstract}

\section{Introduction}

Partitioning between convective and nonconvective cloud regions is important for assessing storm hazards and their effects on the environment. Multiple algorithms have been developed to perform convective-stratiform partitioning using precipitation radars (Awaka et al. 2007, 2016), passive microwave imagers (Anagnostou and Kummerow 1997; Hong et al. 1999; Olson et al. 2001), and multispectral imagers such as the Advanced Baseline Imager (ABI; Schmit et al. 2005) on the NOAA Geostationary Observational Environmental Satellites (GOES) (Liu et al. 2019). Each of these algorithms identifies patterns in the amplitudes or gradients of

Corresponding author: Michael Peterson, mpeterson@lanl.gov the radiance/reflectivity data that are characteristic of convective or stratiform clouds.

Some of these patterns are based on signatures of microphysical features in convective or stratiform clouds. For example, Awaka's radar-based cloud-type algorithms attempt to resolve the radar bright band caused by melting precipitation in the stratiform region. Others rely on qualitative aspects of convective and stratiform clouds-for example, that convective clouds are tall and textured while stratiform clouds are comparably low and smooth. This type of classification lends itself well to computational/statistical pattern recognition methods including machine learning. For example, the ABI cloud-type algorithm published by Liu et al. (2019) uses a deep neural network (DNN) machine learning scheme to determine which combination of visible and 
infrared spectral parameters optimizes the convectivestratiform classification problem.

While the Liu et al. (2019) algorithm performs reasonably well on the validation data, it is not clear why this specific combination of spectral parameters is best from a physics perspective, or whether it is applicable for all regions and storm types. The study area encompassed the East Coast of the United States from South Carolina to Delaware, and the two depicted cases occurred in the same 1800-1830 UTC window on different days. The study did not include analyses of mature mesoscale convective systems (MCSs) over the Great Plains in North America or the La Plata Basin in South America-both within the ABI field of view (FOV). These storms produce some of the largest active stratiform regions on Earth and tend to occur late in the day (and overnight), which may cause issues in how the Liu et al. (2019) algorithm interprets radiances from the visible ABI bands.

Both physics-based and machine learning algorithms have merit in research and applications, but they differ in the type of perspective and depth of insight into the inner-workings of convective systems that they provide. For this reason, it is advantageous to combine multiple approaches from multiple instruments to produce a comprehensive cloud-type assessment.

The Geostationary Lightning Mapper (GLM) may be able to contribute its own, independent, assessment of thunderstorm cloud types based on lightning physics. While the common perception of lightning is that it is a primarily vertical process-either between different charge layers in the cloud, or between the cloud and the ground-the vertical extent of normal lightning is limited to the height of the tropopause $(10-20 \mathrm{~km}$ depending on the location and season). In the horizontal direction, however, lightning propagation is only limited by the extent of the electrified cloud that it can access and the favorability of the thunderstorm charge structure for lateral development.

Laterally extensive lightning is most common outside of the convective core in overhanging anvils (Kuhlman et al. 2009; Weiss et al. 2012) and precipitating stratiform regions (Carey et al. 2005) where charged particles advected from the convective core collect into horizontally expansive layers. These charge layers can be enhanced by local in situ charging mechanisms (Ely et al. 2008; Lang and Rutledge 2008), and the electric fields that they establish are favorable for lateral development (Coleman et al. 2008).

Overhanging anvil clouds and stratiform clouds are generally distinguished in the atmospheric electricity literature due to the considerable differences in their vertical precipitation and charge structures. Overhanging anvils often have one primary charge layer with oppositepolarity screening layers along the upper and lower cloud boundaries (Marshall et al. 1989). Stratiform clouds, on the other hand, can have as many as six expansive layers (up to $100 \mathrm{~km}$ across) stacked on top of one another with alternating polarities between layers (Krehbiel 1986; Marshall and Rust 1993; Stolzenburg et al. 1994; Lang et al. 2004; Marshall et al. 2009).

However, despite these differences in charge structure, both of these nonconvective cloud types are known to produce similar types of primarily horizontal lightning flashes. "Anvil crawlers," "spider lightning," and "sheet lightning" are common names given to flashes that propagate laterally through anvil and stratiform clouds. These propagating flashes can be accurately mapped in three-dimensions over regionalscale domains by ground-based Lightning Mapping Arrays (LMA; Rison et al. 1999) or mapped in twodimensions over very large domains by space-based lightning imagers. The GLM (Goodman et al. 2013; Rudlosky et al. 2019) on the R series of GOES satellites can reveal the lateral development of lightning anywhere within its staring hemispheric-scale FOV.

This study introduces GLM to the problem of cloudtype classification. We aim to differentiate between electrified convective and nonconvective clouds based on the prevalence of propagating flashes that pass through them. A lightning-based cloud-type algorithm is constructed that partitions between electrified convective and nonconvective (anvil or stratiform) clouds. This algorithm is then used to construct a GLM anvil/stratiform cloud probability gridded product. GLM enables realtime product generation with a rapid update cycle (up to every 20 s) across the combined GOES-16 and GOES-17 domain that stretches from New Zealand eastward nearly to the west coast of Africa during the day and at night. Our lightning-based cloud-type product could thus provide situational awareness across a broad domain and complement the existing cloud-type products.

\section{Data and methodology}

Our core hypothesis is that a disproportionate fraction of the high-speed ( $\leq 2 \mathrm{~ms}$ ) optical lightning pulses illuminating nonconvective clouds are produced by horizontally propagating flashes. This would be due to not only low flash rates and a preference for lateral development outside of the convective core but also the fact that propagating flashes generate more pulses per flash than normal lightning (Peterson 2019a). We test the validity of this hypothesis by computing the prevalence of propagating flashes that pass through convective and 
anvil/stratiform cloud regions. This requires two independent types of orbital measurements: optical lightning data from NASA and NOAA lightning imagers are used to identify propagating flashes by mapping their lateral extents, while precipitation radar data are used to verify the cloud type.

\section{a. Lightning imager measurements}

The two lightning imagers that we consider are the Lightning Imaging Sensor (LIS; Christian et al. 2000) on the Tropical Rainfall Measuring Mission (TRMM; Kummerow et al. 1998) satellite and GLM on the GOES-16 satellite (Goodman et al. 2013). TRMM operated for 17 years from late 1997 until mid-2015, but we will only be considering observations taken between January 1998 and March 2014. We limit the TRMM record to ensure that the instruments in its meteorological sensor package were operating simultaneously under nominal conditions. The TRMM satellite spent its life in low Earth orbit (LEO) providing 1-2 min snapshots of lightning activity and thunderstorm precipitation structure across the tropics (up to $36^{\circ}$ latitude) over a combined swath for all instruments that was $215 \mathrm{~km}$ across. Individual instruments (such as LIS) had considerably larger FOVs, but only this narrow swath had measurements from all TRMM sensors (Kummerow et al. 1998).

The GOES-16 satellite, meanwhile, was launched in November 2016 and currently resides in the GOES-East position $\left(75.2^{\circ} \mathrm{W}\right)$. Its geostationary orbit at nearly $35800 \mathrm{~km}$ altitude enables GOES-16 to loiter over the same satellite subpoint location. This orbit allows its instruments-including GLM-to continuously stare at the same geographic region for the duration of its mission. The GOES-16 GLM FOV covers the entire North and South American continents to $54^{\circ} \mathrm{N} / \mathrm{S}$ latitude.

LIS and GLM measure lightning by recording rapid changes in cloud-top radiance over a narrow band around the $777.4 \mathrm{~nm}$ oxygen emission line triplet (Benz et al. 2019). Individual pixels that light up above the background level during one 2-ms frame are termed "events." Clusters of events that light up all at once during the same 2-ms frame and represent the illuminated potion of the thundercloud are known as "groups." Groups that occur close to one another in space and time are then clustered into lightning "flashes." Flash clustering is performed in geolocated space using a weighted Euclidian distance (WED) model described in Mach et al. (2007) for LIS and Goodman et al. (2010) for GLM.

We use a preliminary GLM "science" dataset (Peterson 2019a, 2020) that has been produced for the first calendar year of provisional GOES-16 GLM measurements (January to December 2018). This postprocessed dataset reclusters complex flashes that are artificially split by the GLM ground system and constructs "series" features that exist between the group and flash levels (Peterson and Rudlosky 2019). The parent-child relationships between these features are useful for examining how the trigger times, centroid positions, and reported energies of groups/events characterize flashes (Peterson and Liu 2013); for describing how optical lightning emissions interact with the cloud medium (Peterson et al. 2017b; Peterson 2019b); and for mapping the lateral flash development over time (Peterson et al. 2017a, 2018). This "reclustered" dataset is produced routinely with a typical latency of 3-5 min from real time-on par with ABI CONUS scans.

While most flashes repeatedly illuminate the same cloud region, propagating flashes develop horizontally over many kilometers between first light and the final optical pulse. Propagating flashes typically are defined as having groups that are separated by a distance greater than the characteristic radius of the flash (the size of the flash footprint if it illuminated the same cloud-top area but were perfectly circular) (Peterson et al. 2017a). This definition eliminates the boundary cases that may or may not have horizontal structure, but it alone is not sufficient for cloud-type identification. Lateral development is not entirely lacking in convective regions, but due to limited thunderstorm sizes and thick clouds preventing dim optical pulses from being resolved, convective propagating flashes tend to be small. Thus, we impose an additional minimum size restriction that propagating flashes must be at least $20 \mathrm{~km}$ for LIS or $50 \mathrm{~km}$ for GLM to be considered in this study. These thresholds are arbitrary but chosen after extensive case analysis to balance the probability of detection with the false alarm rate. The GLM threshold is higher because its clustering algorithm delineates flashes from the separation of events rather than group centroids, causing nearby convective flashes to be grouped into single "propagating" flashes, which is undesirable for assessing cloud types.

Rather than examining individual propagating flashes or the proportions of propagating flashes in larger thunderstorms, we leverage the flash extent density (FED) concept to produce grids that show how often each pixel is illuminated by propagating flashes. This will allow us to generate maps that quantify the likelihood that different regions in a thunderstorm are convective or anvil/stratiform clouds. GLM FEDs count the number of unique flashes that illuminate a given pixel on the grid. We modify this formulation by weighting each flash according to the number of groups that it contains. This group-weighted FED (GFED) ensures that propagating flashes having low 
flash rates but very high group counts stand out in contrast to the ubiquitous convective lightning.

\section{b. Precipitation Radar measurements and cloud-type retrieval}

TRMM and its successor Global Precipitation Measurement (GPM; Hou et al. 2014) Core Observatory satellite feature Precipitation Radars (PRs) in their scientific payloads. The TRMM PR and GPM's DualFrequency PR (DPR) record three-dimensional reflectivity maps of the rainclouds below each satellite. An example PR reflectivity cross section through the convective line (left) and into the stratiform region (right) of an MCS is shown in Fig. 1a alongside TRMM Visible and Infrared Scanner (VIRS) infrared brightness temperatures. PR pixels represent a cloud volume that is $\sim 4 \mathrm{~km}$ across and $0.25 \mathrm{~km}$ deep, providing a detailed view of the precipitation structure of the thunderstorm (albeit within a limited FOV). For both TRMM and GPM, the PR/DPR had the narrowest swath of the meteorological instruments and thus limited the extent of the multi-instrument measurement domain.

Retrieval algorithms have been developed to partition PR/DPR pixels into convective, stratiform, and "other" categories (Awaka et al. 2007, 2016). Figure 1b shows an example cloud-type map from the TRMM 2A23 algorithm (Awaka et al. 1997). PR pixels with an apparent radar bright band (at $\sim 4 \mathrm{~km}$ altitude in the reflectivity cross section in Fig. 1a) are classified as stratiform in Fig. 1b. Other is a catchall category that identifies pixels that lack the prominent features used for convectivestratiform partitioning or that lack sufficiently strong radar echoes for the PR to resolve.

A two-step process is used to identify the PR/DPR pixels that correspond to LIS and GLM lightning events within the combined lightning imager and PR/DPR domains. We first regrid the radar pixels to emulate the LIS/GLM pixel sizes using a mathematical mode function (i.e., which PR/DPR cloud type contributes the most matching pixels from the original instrument grid) to choose a prevailing cloud type for the new pixel. We then locate the PR/DPR pixel in the new grid that corresponds to each LIS/GLM event using a nearestneighbor algorithm. For TRMM PR/LIS collocations, we consider all lightning events within the same orbit as the PR data. For GPM DPR/GLM collocations, we consider all lightning within a 15 -min window surrounding the DPR time stamp reported for each scan. This window is chosen to increase the sample size of matching events and maximize GLM detection in lowflash-rate stratiform regions.

For every unique LIS/GLM pixel illuminated during the orbit/time window, we compute the total GFED and
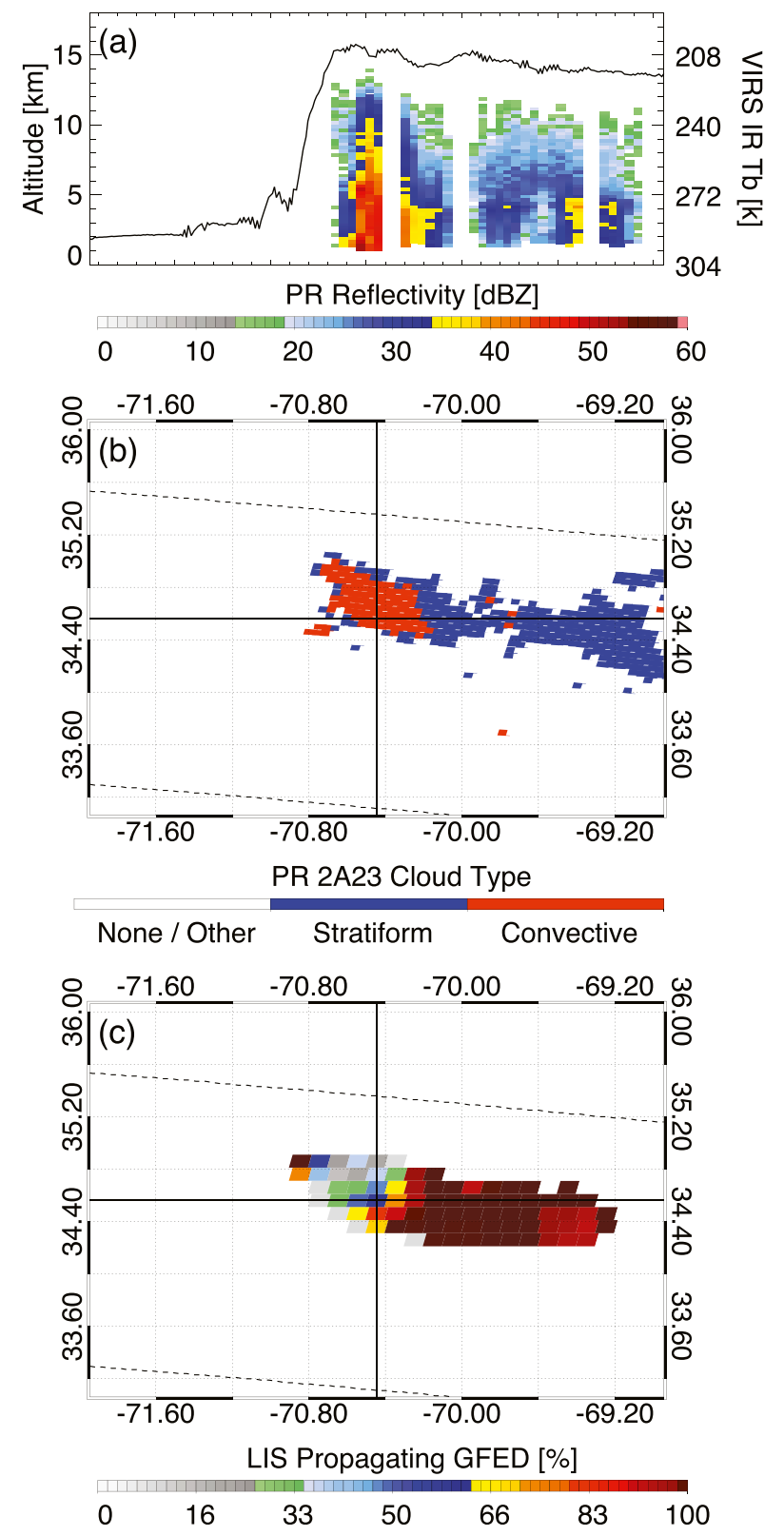

FIG. 1. An example TRMM overpass of a thunderstorm with lightning in the convective and stratiform regions. (a) PR reflectivity and VIRS infrared brightness temperature zonal cross section through the center of the thunderstorm (horizontal line in later panels). (b) TRMM PR 2A23 algorithm cloud types across the storm. (c) The percent of the LIS group weighed flash extent density (GFED) provided by propagating flashes. PR stratiform pixels are almost exclusively illuminated by horizontal lightning.

the GFED from just propagating flashes by incrementing each pixel touched by a flash by the number of groups in that flash. We then take the ratio of these two grids to compute the percent of the GFED that is contributed by propagating flashes in each pixel. The GFED 
LIS Anvil / Strat Cloud Probability

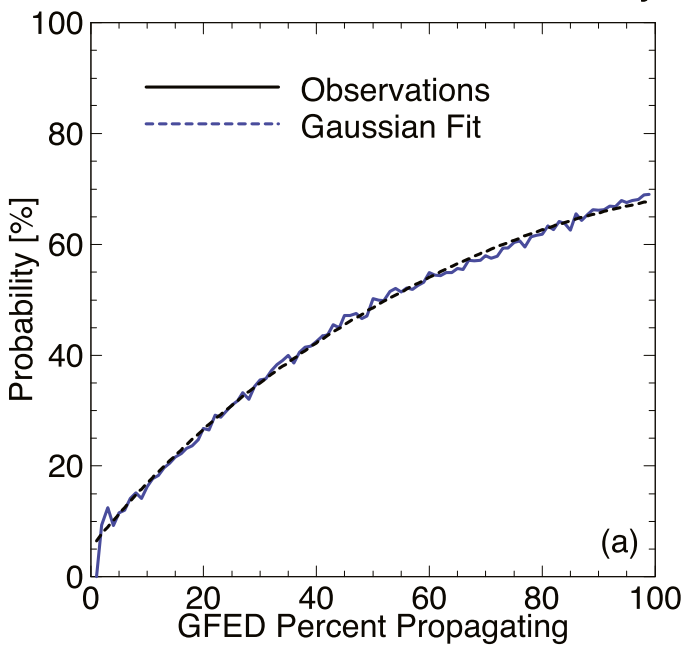

GLM Anvil / Strat Cloud Probability

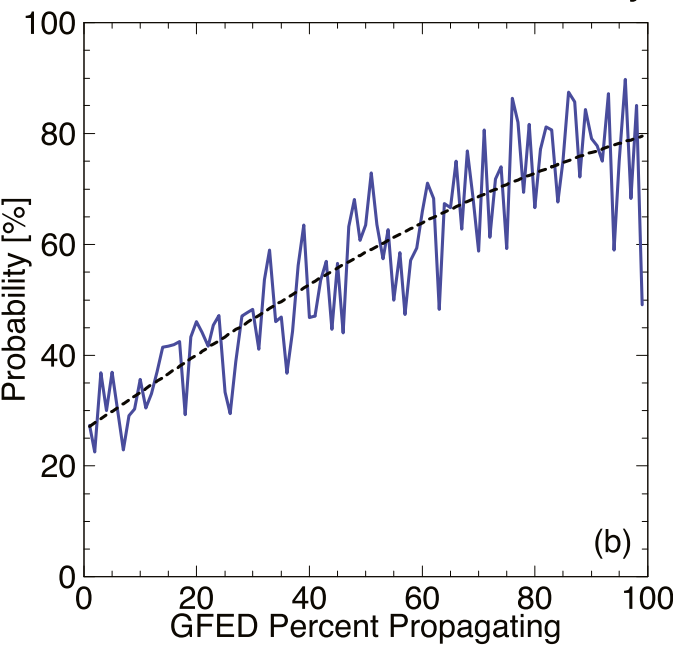

FIG. 2. (a) Probabilities that a given collocated lightning imager/precipitation radar pixel is anvil or stratiform cloud based on the fraction of the group weighed flash extent density (GFED) that is contributed by propagating lightning. TRMM PR cloud types are compared with LIS. (b) GPM DPR cloud types are compared with GOES-16 GLM collocations. Anvil/stratiform cloud probabilities increase with the GFED percent propagating in both cases.

percent propagating for the thunderstorm in Figs. 1a and $1 \mathrm{~b}$ is shown in Fig. 1c. Grid points designated as stratiform by the TRMM PR have propagating GFED fractions close to $100 \%$, while convective regions have lower propagating flash fractions. We collect the PR/DPR classifications (Fig. 1b) and LIS/GLM propagating GFED fractions (Fig. 1c) for pixels illuminated by lightning into separate databases for TRMM and GPM/GLM.

\section{Results}

The databases of coincident lightning imager and precipitation radar measurements described in section 2 are used to compute the probability that a given pixel is an anvil/stratiform cloud rather than a convective cloud based on how often it is illuminated by propagating lightning. The 16-yr TRMM database contains 30 million collocated LIS/PR pixels, while the 4-month GOES-16/GPM database contains only 84000 common GLM/DPR pixels. Though GLM records 20 times more lightning per year than LIS observed over its entire mission (due to its geostationary orbit), GPM is still a LEO satellite and its infrequent narrow snapshots restrict the accumulation rate of coincident pixels over the common measurement domain of the two satellites.

Figure 2 shows the probabilities that a given pixel is an anvil/stratiform cloud by comparing 1 ) the propagating TRMM LIS GFED fraction with the TRMM PR cloud type (Fig. 2a) and 2) the GOES-16 GLM GFED fraction with the GPM DPR cloud type (Fig. 2b). Probabilities are calculated by finding all matching pixels with a certain GFED value ( $x$ axis; bin size is $1 \%$ ) and then computing the percent of the sample where the radar reports a nonconvective cloud type. Both probability curves increase with GFED propagating fraction, but the starting and ending probabilities differ between TRMM and GOES-16/GPM. This is likely due to differences in the lightning imagers rather than the precipitation radars since LIS and GLM feature different sensitivities, pixel sizes, and viewing geometries (e.g., GLM must contend with the curvature of Earth near the edge of its FOV). The GLM (LIS) event-based flash clustering (group-centroid-based clustering) and the resulting $50 \mathrm{~km}(20 \mathrm{~km})$ threshold value also contribute to these differences. Furthermore, the relatively small sample size of GLM/GPM collocations is responsible for the increased noise in Fig. $2 b$.

The probability curves in Fig. 2 can be used to convert the GFED gridded product in Fig. 1c into probabilistic cloud-type maps. We fit a Gaussian curve to the data in Fig. 2b for GLM and use this regression to calculate anvil/stratiform cloud probabilities. Figure 3 shows GOES-16 ABI channel $14(11.2 \mu \mathrm{m})$ infrared brightness temperatures (top) and GLM anvil/stratiform cloud probabilities (bottom) at two points during a large frontal system that moved through the south-central United States between 13 and 17 April 2018. The overall evolution of this storm was analyzed in detail in 
04/13/2018 22:00:00 UTC

$\begin{array}{lllllll}-98 & -96 & -94 & -92 & -90 & -88 & -86\end{array}$

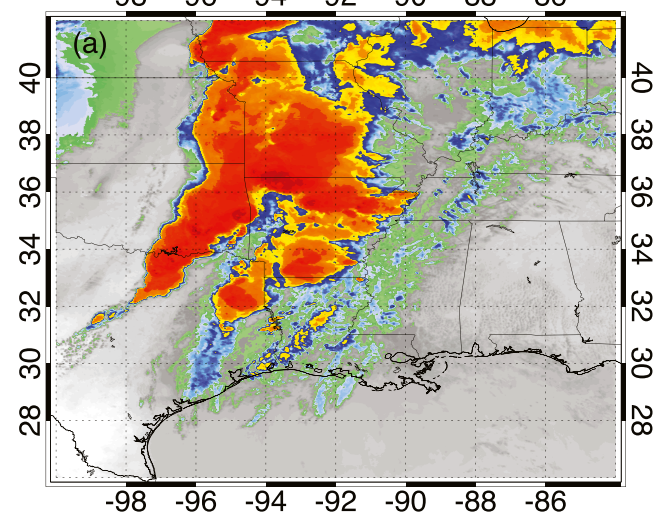

ABI CH14 IR Brightness Temperature [ K ]

302290278266254242230218206194

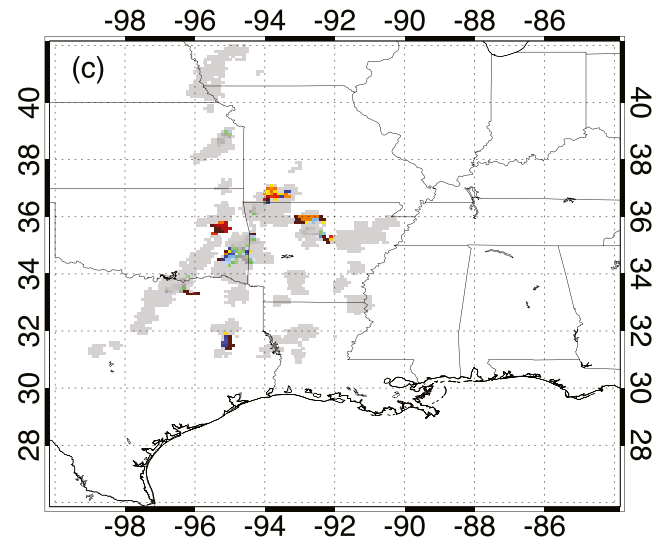

GLM Anvil / Stratiform Cloud Probability [\%]

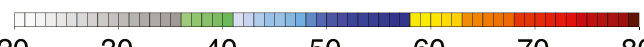

04/14/2018 07:00:00 UTC

$\begin{array}{lllllll}-98 & -96 & -94 & -92 & -90 & -88 & -86\end{array}$

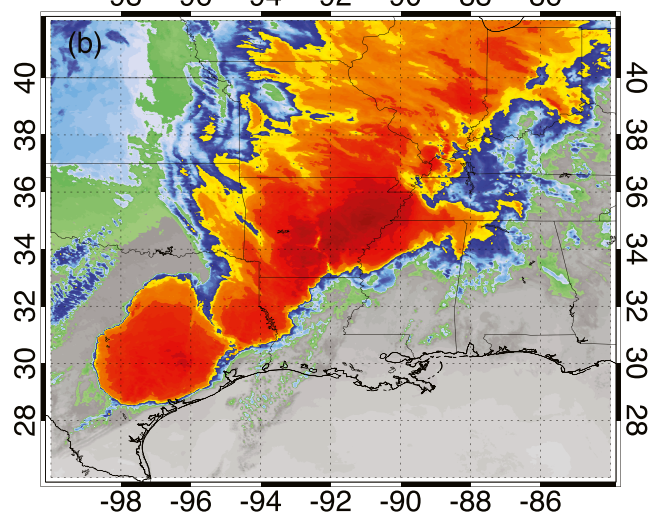

ABI CH14 IR Brightness Temperature [ K ]

302290278266254242230218206194

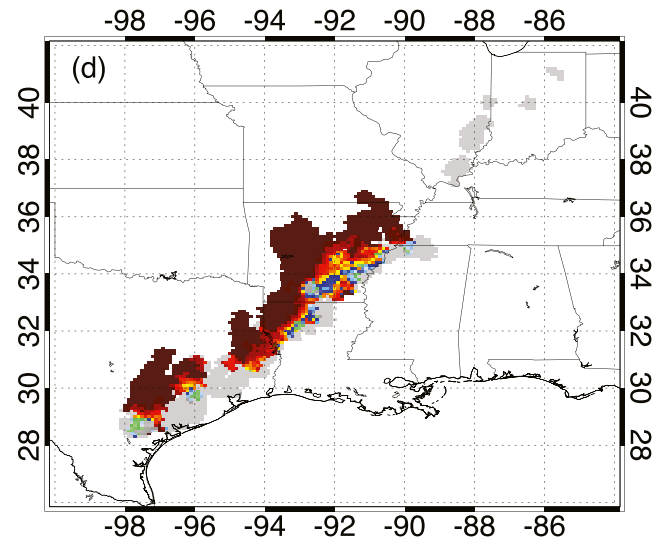

GLM Anvil / Stratiform Cloud Probability [\%]

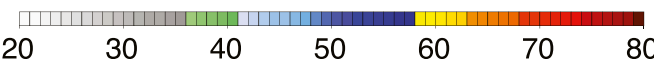

FIG. 3. (a),(b) GOES-16 snapshots of ABI channel 14 infrared brightness temperature and (c),(d) the GLM anvil/stratiform cloud probability gridded product during two key points in the history of a frontal system that persisted for multiple days (13-17 Apr 2018) as it crossed the southeastern United States.

Peterson et al. (2020) and it was not included in the training dataset of GLM/DPR coincident measurements.

The first time of interest (Figs. 3a,c) is 2200 UTC 13 April 2018 when the storm was least organized, consisting of 50 distinct ABI cold cloud $(<235 \mathrm{~K})$ features. Up until this point, the GLM recorded very few propagating flashes, with most lightning having little lateral development (i.e., primarily vertical). However, propagating flashes were becoming increasingly common and starting to dominate the GFEDs between convective cells. These regions reported $>50 \%$ anvil/stratiform cloud probabilities (Fig. 3c), but they still accounted for a small fraction of the overall thunderstorm area.

Over the next $9 \mathrm{~h}$, the storm system reached its peak overall flash rate and began maturing. It organized into just two distinct ABI cold cloud features as it achieved its peak overall extent, encompassing nearly $50000 \mathrm{ABI}$ pixels (Fig. 3b). While the flash rate for the system decreased, flash sizes increased and propagating flash activity reached a peak of $13 \%$ of all lightning produced by the storm. GLM anvil/stratiform cloud probabilities (Fig. 3d) show that these propagating flashes were confined to the trailing stratiform region along the rear flank of the storm. Anvil/stratiform cloud probabilities exceeded $80 \%$ behind the line while the forward flank maintained probabilities below $30 \%$, except where propagating flashes were observed in the forward anvil (southeastern Missouri).

The domain covered by GLM lightning activity in Fig. $3 \mathrm{~d}$ is significantly smaller than the ABI storm 
feature shown in Fig. 3b. The stratiform region certainly extends beyond the lightning core where we have data to make our assessments; however, the strongest part of the storm that poses the greatest hazard to the general public is mapped contiguously by the GLM algorithm.

\section{Summary}

This study documents the construction of a lightningbased cloud-type algorithm that differentiates between electrified convective and anvil/stratiform clouds based on how frequently they are illuminated by horizontally propagating lightning flashes. Such flashes are not typical of normal convective lightning that develops primarily in the vertical direction. The propagating flashes that are generally observed in anvil/stratiform clouds develop laterally over considerable distances (tens to hundreds of kilometers), and this allows them to be identified in space-based lightning imager measurements.

We use coincident measurements between the LIS and PR instruments on the TRMM satellite and between GLM on the GOES-16 satellite and the DPR on the GPM satellite to compare propagating flash frequencies with radar-based cloud types. Making these comparisons at the pixel level allows us to assess the likelihood that a given grid point represents an electrified anvil/stratiform cloud based on the percent of all lightning illuminating it that is contributed by propagating flashes.

The end result is a GLM anvil/stratiform cloud probability gridded product (Figs. 3c,d) that can be produced for the combined GOES-16 and GOES-17 GLM domain. These analyses can complement existing cloud-type algorithms including a recently published ABI algorithm that uses machine learning to identify convective and stratiform clouds. The ABI algorithm can classify regions that do not produce lightning, but it is a daytime algorithm that relies on the visible channels. As both meteorological instruments on the GOES satellites (GLM and ABI) can be used to assess cloud type, we propose the future creation of a merged GOES cloud-type product that could benefit from the strengths of each instrument and approach to provide a comprehensive cloud-type assessment for the operations and research communities.

Acknowledgments. This study was supported by NASA Grant NNX17AH63G. The LIS science dataset is available online from the NASA Global Hydrology Resource Center DAAC, Huntsville, Alabama, United States. The GLM LCFA and ABI datasets may be obtained from NOAA via their CLASS service. GLM
LCFA-R data may be obtained from our public data repository at data.wxarch.com (Peterson et al. 2020).

\section{REFERENCES}

Anagnostou, E. N., and C. Kummerow, 1997: Stratiform and convective classification of rainfall using SSM/I $85-\mathrm{GHz}$ brightness temperature observations. J. Atmos. Oceanic Technol., 14, 570-575, https://doi.org/10.1175/1520-0426(1997) $014<0570$ :SACCOR $>2.0 . \mathrm{CO} ; 2$.

Awaka, J., T. Iguchi, H. Kumagai, and K. I. Okamoto, 1997: Rain type classification algorithm for TRMM precipitation radar. Proc. 1997 IEEE Int. Geoscience and Remote Sensing Symp.-A Scientific Vision for Sustainable Development (IGARSS'97), Vol. 4, Singapore, IEEE, 1633-1635, https://doi.org/10.1109/ IGARSS.1997.608993.

, - — , and K. I. Okamoto, 2007: Rain type classification algorithm. Measuring Precipitation from Space: EURAINSAT and the Future, V. Levizzani, P. Bauer, and F. J. Turk, Eds., Springer, 213-224.

, M. Le, V. Chandrasekar, N. Yoshida, T. Higashiuwatoko, T. Kubota, and T. Iguchi, 2016: Rain type classification algorithm module for GPM dual-frequency precipitation radar. J. Atmos. Oceanic Technol., 33, 1887-1898, https://doi.org/ 10.1175/JTECH-D-16-0016.1.

Benz A., M. Leand Coauthors, 2019: GOES-R Series Data Book. NASA GOES-R Series Program Office, 240 pp., https:/www.goes-r.gov/downloads/resources/documents/GOESRSeriesDataBook.pdf.

Carey, L. D., M. J. Murphy, T. L. McCormick, and N. W. S. Demetriades, 2005: Lightning location relative to storm structure in a leading-line, trailing-stratiform mesoscale convective system. J. Geophys. Res., 110, D03105, https://doi.org/ 10.1029/2003JD004371.

Christian, H. J., R. J. Blakeslee, S. J. Goodman, and D. M. Mach, Eds., 2000: Algorithm Theoretical Basis Document (ATBD) for the Lightning Imaging Sensor (LIS). NASA/Marshall Space Flight Center, $53 \mathrm{pp}$.

Coleman, L. M., M. Stolzenburg, T. C. Marshall, and M. Stanley, 2008: Horizontal lightning propagation, preliminary breakdown, and electric potential in New Mexico thunderstorms. J. Geophys. Res., 113, D09208, https://doi.org/10.1029/ 2007JD009459.

Ely, B. L., R. E. Orville, L. D. Carey, and C. L. Hodapp, 2008: Evolution of the total lightning structure in a leading-line, trailing-stratiform mesoscale convective system over Houston, Texas. J. Geophys. Res., 113, D08114, https://doi.org/10.1029/ 2007JD008445.

Goodman, S. J., D. Mach, W. J. Koshak, and R. J. Blakeslee, 2010: GLM Lightning Cluster-Filter Algorithm (LCFA). Algorithm Theoretical Basis Doc., 73 pp., https://www.star.nesdis.noaa.gov/ goesr/documents/ATBDs/Baseline/ATBD_GOES-R_GLM_ v3.0_Jul2012.pdf.

, and Coauthors, 2013: The GOES-R Geostationary Lightning Mapper (GLM). Atmos. Res., 125-126, 34-49, https://doi.org/ 10.1016/j.atmosres.2013.01.006

Hong, Y., C. D. Kummerow, and W. S. Olson, 1999: Separation of convective and stratiform precipitation using microwave brightness temperature. J. Appl. Meteor., 38, 1195-1213, https:// doi.org/10.1175/1520-0450(1999)038<1195:SOCASP > 2.0.CO;2.

Hou, A. Y., and Coauthors, 2014: The Global Precipitation Measurement mission. Bull. Amer. Meteor. Soc., 95, 701-722, https://doi.org/10.1175/BAMS-D-13-00164.1. 
Krehbiel, P. R., 1986: The electrical structure of thunderstorms. The Earth's Electrical Environment, E. P. Krider and R. G. Roble, Eds., National Academies Press, 90-113.

Kuhlman, K. M., D. R. MacGorman, M. I. Biggerstaff, and P. R. Krehbiel, 2009: Lightning initiation in the anvils of two supercell storms. Geophys. Res. Lett., 36, L07802, https://doi.org/ 10.1029/2008GL036650.

Kummerow, C., W. Barnes, T. Kozu, J. Shiue, and J. Simpson, 1998: The Tropical Rainfall Measuring Mission (TRMM) sensor package. J. Atmos. Oceanic Technol., 15, 809-817, https://doi.org/ 10.1175/1520-0426(1998)015<0809:TTRMMT>2.0.CO;2.

Lang, T. J., and S. A. Rutledge, 2008: Kinematic, microphysical, and electrical aspects of an asymmetric bow-echo mesoscale convective system observed during STEPS 2000. J. Geophys. Res., 113, D08213, https://doi.org/10.1029/2006JD007709.

, -, and K. C. Wiens, 2004: Origins of positive cloud-toground lightning flashes in the stratiform region of a mesoscale convective system. Geophys. Res. Lett., 31, L10105, https:// doi.org/10.1029/2004GL019823.

Liu, Q., Y. Li, M. Yu, L. S. Chiu, X. Hao, D. Q. Duffy, and C. Yang, 2019: Daytime rainy cloud detection and convective precipitation delineation based on a deep neural Network method using GOES-16 ABI images. Remote Sens., 11, 2555, https:// doi.org/10.3390/rs11212555.

Mach, D. M., H. J. Christian, R. J. Blakeslee, D. J. Boccippio, S. J. Goodman, and W. L. Boeck, 2007: Performance assessment of the optical transient detector and lightning imaging sensor. J. Geophys. Res., 112, D09210, https://doi.org/10.1029/2006JD007787.

Marshall, T. C., and W. D. Rust, 1993: Two types of vertical electrical structures in stratiform precipitation regions of mesoscale convective systems. Bull. Amer. Meteor. Soc., 74, 2159-2170, https:// doi.org/10.1175/1520-0477(1993)074<2159:TTOVES>2.0.CO;2.

, W. P. Winn, and K. E. Gilbert, 1989: Electrical structure in two thunderstorm anvil clouds. J. Geophys. Res., 94, 21712181, https://doi.org/10.1029/JD094iD02p02171.

—, M. Stolzenburg, P. R. Krehbiel, N. R. Lund, and C. R. Maggio, 2009: Electrical evolution during the decay stage of New Mexico thunderstorms. J. Geophys. Res., 114, D02209, https://doi.org/10.1029/2008JD010637.

Olson, W. S., Y. Hong, C. D. Kummerow, and J. Turk, 2001: A texturepolarization method for estimating convective-stratiform precipitation area coverage from passive microwave radiometer data. J. Appl. Meteor., 40, 1577-1591, https://doi.org/10.1175/15200450(2001)040<1577:ATPMFE > 2.0.CO;2.

Peterson, M., 2019a: Research applications for the Geostationary Lightning Mapper operational lightning flash data product. J. Geophys. Res. Atmos., 124, 10 205-10231, https://doi.org/ 10.1029/2019JD031054.
_ 2019b: Using lightning flashes to image thunderclouds. J. Geophys. Res. Atmos., 124, 10175-10185, https://doi.org/ 10.1029/2019JD031055.

_ 2020: Removing solar artifacts from Geostationary Lightning Mapper data to document lightning extremes. J. Appl. Remote Sens., 14, 032402, https://doi.org/10.1117/1.JRS.14.032402.

— and C. Liu, 2013: Characteristics of lightning flashes with exceptional illuminated areas, durations, and optical powers and surrounding storm properties in the tropics and inner subtropics. J. Geophys. Res. Atmos., 118, 11727-11740, https://doi.org/10.1002/JGRD.50715.

_ and S. Rudlosky, 2019: The time evolution of optical lightning flashes. J. Geophys. Res. Atmos., 124, 333-349, https://doi.org/ 10.1029/2018JD028741.

— W. Deierling, C. Liu, D. Mach, and C. Kalb, 2017a: The properties of optical lightning flashes and the clouds they illuminate. J. Geophys. Res. Atmos., 122, 423-442, https:// doi.org/10.1002/2016JD025312.

—, S. Rudlosky, and W. Deierling, 2017b: The evolution and structure of extreme optical lightning flashes. J. Geophys. Res. Atmos., 122, 13 370-13 386, https://doi.org/10.1002/2017JD026855.

,-- , and -2018 : Mapping the lateral development of lightning flashes from orbit. J. Geophys. Res. Atmos., 123, 9674-9687, https://doi.org/10.1029/2018JD028583.

— _ _ and D. Zhang, 2020: Changes to the appearance of optical lightning flashes observed from space according to thunderstorm organization and structure. J. Geophys. Res. Atmos. 125, e2019JD031087, https://doi.org/10.1029/2019JD031087.

Rison, W., R. J. Thomas, P. R. Krehbiel, T. Hamlin, and J. Harlin, 1999: A GPS-based three-dimensional lightning mapping system: Initial observations in central New Mexico. Geophys. Res. Lett., 26, 3573-3576, https://doi.org/10.1029/1999GL010856.

Rudlosky, S. D., S. J. Goodman, K. S. Virts, and E. C. Bruning, 2019: Initial Geostationary Lightning Mapper observations. Geophys. Res. Lett., 46, 1097-1104, https://doi.org/10.1029/ 2018 GL081052.

Schmit, T. J., M. M. Gunshor, W. P. Menzel, J. J. Gurka, J. Li, and A. S. Bachmeier, 2005: Introducing the next-generation Advanced Baseline Imager on GOES-R. Bull. Amer. Meteor. Soc., 86, 10791096, https://doi.org/10.1175/BAMS-86-8-1079.

Stolzenburg, M., T. C. Marshall, W. D. Rust, and B. F. Smull, 1994: Horizontal distribution of electrical and meteorological conditions across the stratiform region of a mesoscale convective system. Mon. Wea. Rev., 122, 1777-1797, https://doi.org/ 10.1175/1520-0493(1994)122<1777:HDOEAM > 2.0.CO;2.

Weiss, S. A., D. R. MacGorman, and K. M. Calhoun, 2012: Lightning in the anvils of supercell thunderstorms. Mon. Wea. Rev., 140, 2064-2079, https://doi.org/10.1175/MWR-D-11-00312.1. 